\title{
STRENGTHENING AND SUPPORTING THE SCHOOL COMMUNITIES: A CASE OF REGIONAL SCHOOLS IN LITHUANIA
}

\author{
Lina Kaminskiene1, Virginija Bortkevičienè ${ }^{2}$ \\ 1 Vytautas Magnus University, Lithuania; University of Latvia, Latvia \\ ${ }^{2}$ Kaunas University of Technology, Lithuania; University of Latvia, Latvia
}

\begin{abstract}
The paper discusses how the school microclimate could be improved within the school community, based on the results of a research carried out in 15 regional schools in Lithuania. The analysis is specifically focused on how the school community could be strengthened by improving the relationship between teachers and schools' administration. Following the methodology of the thematic analysis, the paper highlights key issues which might be important to reconsider the formation of a positive relationship, internal communication, democratization of governance, reduction of competition between teachers, strengthening the confidence in the teacher, respect for each other as well as fostering an open, tolerant culture. The results of the research indicate the need to strengthen collaboration and engagement-based community: a need to develop a participatory culture, to develop teachers' support systems, to rethink how to involve parents more actively into the school life, to ensure more effective feedback system (teachers-administration-parents). The paper also highlights a need to improve the emotional climate of schools, to develop clear guidelines for evaluating teachers' activities, to ensure smooth internal communication, informing and involving teachers about planned changes, and allowing all members of the community to feel part of the organization, not only by informing about the activities being carried out, but also by enabling critical opinions to be expressed; to form different working groups involving different educators (e. g. primary school and subject teachers) on different issues of school performance development.
\end{abstract}

Keywords: community, emotional climate, microclimate, organisational culture, school performance improvement.

\section{Introduction}

There are many reasons for strengthening school community and developing school, the family and community partnerships. A strong school community and the integration of school community in different processes of the school life can bring an added value to several processes: improved 
school programs, better school climate, learning results and achievements of students, shared responsibilities providing family services and support, connected families, better feedback to teachers, created participatory culture. When the communication between parents, teachers, students, and others (e. g., local businesses, community colleges, and health agencies) becomes a collaboration, that builds a partnership between all sides, and everyone benefits. Following the results of the study conducted by Cohen et al. (2009, p. 181) "positive school climate is associated with and/or predictive of academic achievement, school success, effective violence prevention, students' healthy development, and teacher retention".

Studies identified that building school community is important for better learning results and achievements of the learners (Henderson \& Mapp, 2002) and it is noted as a critical factor affecting the success of individual students and the school environment itself. A growing interest of research about the community schools confirms the importance of strengthening community in schools. There are studies which indicate that students in schools with a strong sense of community are more likely to be academically motivated (Lenzi et al., 2017); to act ethically and altruistically, develop understanding of justice (Thomas et al., 2019), to develop social and emotional competencies (Solomon et al., 2000) and to avoid problems in behaviours, including chronic school absence (Van Eck et al., 2017) creating in that sense trust-full environment. Several studies highlighted that schools with strong community have better academic outcomes - higher grade-point averages and achievement test scores (Henderson \& Mapp, 2002), teacher ratings of behaviour - better academic engagement, respectful behaviour, and social skills.

The research about school microclimate and school community confirms the benefits of building a sense of community in schools. The sense of strong community in schools is connected to the culture and the context of the school. Community schools seeks to create a culture of trusting and positive relationships (Brewster \& Railsback, 2003). As authors Harris et al. (2013, p. 4) state, that "a culture of trust enhances performance" which creates a positive microclimate in schools. The paper, thus, aims to analyse the microclimate of the school communities and identify areas for its improvement.

\section{Methodology}

The quantitative research was conducted in 2019 in 15 regional schools in Lithuania. The overall aim was to evaluate the microclimate of schools by assessing work-related psychosocial factors and work satisfaction related questions. The research objectives were addressed to reveal the peculiarities 
of teacher-parent, school administration-teacher relations, to identify the peculiarities of the above-mentioned group communications, conflicts, possible risks and identifying factors influencing the formation of a positive school microclimate.

The study participants were selected using targeted and convenient selection methods. The questionnaire was online and distributed through emails to the selected schools. The sample consisted of 424 school staff 368 teachers, 24 administrative staff and 32 child support specialists. Of these, $35(8.3 \%)$ men and 389 (91.7\%) women aged between 22 and 69 (average 49.2 years).

This paper is based on the analysis of open questions which were given to the research participants. The two open questions addressed positive and negative aspects of the school community. The analysis was done by applying the methodology of thematic analysis (Braun \& Clarke, 2006). The method is characterized by flexibility in data interpretation and includes 6 steps: repeated reading of the text, distinguishing semantic ideas; extraction of quotes from semantic texts and developing initial codes; combining codes into primary themes; review of selected themes and codes; formulation of themes; final analysis of the selected passages of text. An inductive research strategy was used because the themes were formed based on the data from the open-ended questions.

The participants in the study were left space to answer, with a targeted indication of the possibility of making five statements each question. However, the study participants were free to make the desired number of statements or not to answer any questions. The study participants were not given an indication of the need to rank the characteristics of the school community.

\section{Results}

The thematic analysis allowed to identify the repeating themes which reflect positive and negative aspects of the communication between teachers and administration. Three major themes emerged as a result of the data analysis:

- Positive communication

- Management improvement

- Strengthening and mobilizing community.

\section{Positive communication}

One of the evident areas for improvement is related to the strengthening of a positive communication. A positive communication is most needed to be developed between teachers and administration and between teacher 
colleagues. Teachers and administrative staff, child support specialists, who participated in the research, emphasized the following aspects which contribute to the developing a positive communication culture:

- Openness and tolerance.

- Respectful relationship.

- Tension, stress reduction.

- Empathy.

The research participants associate openness and tolerance with tolerance of other opinions, openness between teachers and administration. Openness is associated with non-concealment of truth, more sincere communication. The research participants see openness as a very important aspect that helps building a culture of trust in the community.

Respect is viewed as the foundation of positive communication. The issue of respect was very strongly highlighted in the study and the participants associated it both with warmer communication with each other and with a sense of tact, empathy, and the competence of the administration to resolve conflicts. It should be noted that the aspect of respect is mentioned both in the context of communication between teachers and in communication with schools' leaders.

Tensions in the schools are revealed by the teachers' stated desire to speak calmly, to solve problems without fever, without humiliating others.

\section{Management improvement}

The second aspect is related to the improvement of the management. Management improvement is associated with:

- Democratic spirit, listening, culture of consultation with teachers.

- Objective evaluation of teachers' activities.

- Ensuring internal communication.

- Creating an emotionally safe environment.

- Innovation.

- Cutting red tape.

- Improving infrastructure.

The research revealed that schools' administration should pay more attention to the fact that dialogue and a culture of consultation are very important for a good school microclimate. Teachers' responses indicate that a culture of discussion and negotiation is still underdeveloped. The research participants suggest looking for other forms of meetings, to create conditions for expressing different opinions, which may not always coincide with the position of the administration. The administration needs to build a culture of trust and free thought because there seem to be schools where teachers are afraid, intimidated, and therefore do not feel like full members of the community. 
Objective evaluation of teachers, reduction of competition between teachers is an important aspect too. Teachers expressed the opinion that their activities are not sufficiently evaluated or evaluated biasedly. Teachers feel that the school administration is not sufficiently open to different opinions. There is no developed culture of mutual support, teachers feel a lack of systematic feedback regarding their work and miss a well-functioning and transparent incentive system.

Competition between teachers should not be a norm in schools. Competition in an educational institution brings more harm than good. Representatives of the administration should rethink strategies to ensure objective evaluation of teachers' activities, continuous provision of feedback, and the formation of a support system.

Internal communication is a powerful tool in ensuring that a culture of openness and trust would prevail in the community. The teachers involved in the study indicated that a lot is hidden from them, there is a lack of information, sharing of what is happening and why, the rationale for one or another decision is not always clear. The research results show that it is important for both teachers and school administration to create internal communication systems, they must ensure the continuous provision of information to teachers, and it is also necessary to think about the improvement of communication competencies. The achievements of the whole community, which are described by teachers as initiatives, innovations, also contribute to the formation of a good microclimate.

Creating an emotionally safe environment is linked to issues discussed earlier, such as building a culture of trust, preventing bullying between teachers and students, and promoting teachers 'self-efficacy. The research data show that teachers do not feel emotionally calm and safe, there is a lot of anxiety, fear, a sense of control. There is a lack of unifying activities.

Although the problem of bureaucracy was not dominant in the research participants' answers, its reduction can contribute to improving the microclimate of organizations. Bureaucracy is also perceived as an obstacle to communication between teachers and administration, because everyone has fill in the "paper" properly, and there is little time left for live communication.

The infrastructure improvement is a secondary aspect of the microclimate improvement, but it is associated with a safe physical and emotional environment. Teachers feel inadequate in untidy or long-renovated environments, although they realize that this is not just a consequence of the inability of the school administration. 


\section{Strengthening and mobilizing community}

The third area for improvement is community mobilization and strengthening. It is associated with:

- Building trust in teachers.

- Sharing culture.

- Development of a teacher support system.

- Strengthening communication and cooperation between different educators.

- Improving communication with parents.

A need to strengthen the community is defined by the idea that values and traditions are very important for community mobilization. The participants of the study placed a strong emphasis on the issue of trust in teachers. This testifies the lack of open collaboration in school communities and that teachers feel that the administration, their parents are too critical about their work and thus, teachers' professionalism is not recognized.

One of the tools for strengthening the community, according to the study participants, is the sharing of experiences and work. This view has to do with another aspect: providing help to teachers, instead of being criticized, intimidated, monitored.

Teachers lack understanding, support, and help from the administration. They feel that teachers' initiatives are not encouraged, too little attention is paid to the evaluation of their activities, and too much tension prevails, which hinders the creative work of teachers.

Teachers point to a lack of co-operation, especially in schools where both primary and lower secondary education are provided. Teachers feel that there is a separation between subject and primary school teachers.

Improving communication with parents might also contribute to more positive school microclimate. The research participants note that schools need to think about more active strategies for involving parents in school activities. This should strengthen a community spirit.

\section{Discussion}

The ongoing education reform poses many challenges for teachers and school administration, which in one or another way is linked to their satisfaction with the work done and perceived psychological well-being (Ilgan et al., 2014; Smetackova et al., 2019). The research revealed very important aspects while developing stronger school communities and ensuring a positive microclimate. The most prominent characteristics of the school microclimate are related to the formation of positive and sincere relationships, strengthening of internal communication, democratization of management (listening to different opinions, tolerance of opinion, objective 
evaluation of teachers' activities, etc.), reducing competition between teachers, community and communality, teacher trust, strengthening mutual respect, fostering an open, tolerant culture.

The research results well correlate with similar studies, especially looking at the need to strengthen community in schools, rethinking how to involve parents more actively in school life and ensuring a more effective feedback to them. According to Maier et al. $(2017,13)$ "community schools are organized around four key features (pillars): (1) integrated student supports; (2) expanded learning time and opportunities; (3) family and community engagement; and (4) collaborative leadership and practice". Several of those pillars are very closely related to our research results such as community development, strengthening trust in teachers, collaboration, reducing of competition.

The research results revealed that there is a lack of trust in teachers or between teachers in schools, while the systems of control, monitoring and a sufficiently rigorous assessment prevail, which makes teachers feel fear, tension, competition. Brewster and Railsback (2003, p. 16) also noted, that it very important to create conditions for teacher's collaboration, like "principals can support collaboration by making time in the schedule for teachers to work together, providing training on effective strategies for team-building, and offering incentives for teachers to collaborate". While schools seek to create a culture of trusting relationship, positive collaboration by improving school climate, developing trust between teachers and community members should be as a priority and taking time to develop and to create a culture of trust, should be worth of the investment. According to Blase and Blase (2001, p. 23), "without trust a school cannot improve and grow into the rich, nurturing micro-society needed by children and adults alike".

The research results revealed a need for strengthening a collaborative leadership and good management. Maier et al. (2017, p. 6) also identified, that "the collaborative leadership, practice, and relationships found in community schools can create the conditions necessary to improve student learning and well-being, as well as improve relationships within and beyond the school walls". This was noted as an important development area in the paper as well, that partnerships within and beyond the school's walls is an integral part in creating a positive microclimate and trustful community in schools.

Some very important findings are related to the improvement of students' achievements and learning results as well participation in the school's activities. Studies were made in order to find answers how strong school community could make an added value for the school itself. Those studies bring us some specific evidence that strengthening school community 
improves students' achievements (Anderson et al., 2010; Bryk, 2010;); increases students tests scores (Blank et al., 2003; Sheldon, 2007); increases students attendance rates (Sheldon, 2007; Sheldon, Epstein, 2004).

This research is novel in the fact that it expands qualitative aspects of a positive school microclimate. It reveals what is beneath positive communication at schools and points to such values and attitudes as openness and tolerance, respectful relationship, tension, stress reduction and empathy. Strengthening community is qualitatively associated with trust building, sharing culture, teacher support system development. The new aspect is to focus on communication and cooperation between different teachers: subject teachers and primary teachers and similar, which indicates that teachers understand that collaboration only in their discipline groups might be a limitation while striving for a stronger school community. One important aspect related to the management improvement - cutting red tape is linked to effective school leaders, principals, who might protect their school community from abundant bureaucracy.

\section{Conclusions}

Competition in educational institutions does not contribute to a good institutional microclimate. Administration representatives should rethink strategies to ensure an objective appraisal of teachers' performance, provide a continuous feedback, and ensure the formation of the support system.

School communities lack a trust in teachers, while the systems of control, monitoring and a sufficiently rigorous evaluation prevail, which makes teachers feel fear, tension, competition, division into 'loved ones' and 'unloved'.

The research results show that schools' administration does not pay enough attention to individualized and collegial appraisal of teachers' activities. It is proposed that school administrations could apply a continuous method of evaluation of teachers' activities based on the individual and group reflection. Feedback to teachers should be based on a positive and critical paradigm involving all members of the community, i. e., systematically applying an evaluation based on the views of teachers, administrations, parents and pupils themselves.

The results of the research identified the need to strengthen community in schools, i. e., a culture based on the engagement of all members (formation of a participating culture) and rethink how to involve parents more actively in school life, ensuring a more effective feedback to them.

The school community might be strengthened through the developed teacher support systems and sharing best practices scaffolding young teachers who lack experience or competence. 
For the schools' principals it is important to ensure that everyone's voices and opinions are heard in schools, to allow all members of the community to feel part of the organization not only by informing about the activities carried out, but also by providing the opportunity to express critical opinions; to form different working groups involving teachers (e. g., primary education and subject teachers) on different issues of improving school performance. The last but not the least schools should learn how to disseminate and share the achievements of school communities.

\section{References}

Anderson, J. A., Houser, J. H., \& Howland, A. (2010). The Full Purpose Partnership Model for Promoting Academic and Socio-Emotional Success in Schools. School Community Journal, 20, 31-54.

Blank, M. J., Melaville, A., Shah, B. P. (2003). Making the difference: Research and practice in community schools. Coalition for Community Schools.

Blase, J., Blase, J. (2001). The Teacher's Principal. Journal of Staff Development, 22(1), 22-25.

Braun, V., Clarke, V. (2006) Using thematic analysis in psychology. Qualitative Research in Psychology, 3 (2), 77-101.

Brewster, C., Railsback, J. (2003). Building Trusting Relationships for School Improvement: Implications for principals and teachers. Northwest Regional Educational Lab., Portland.

Bryk, A. (2010). Organizing schools for improvement. Kappan Magazine, 91(7), 23-30.

Cohen, J., E. M. McCabe, N. M. Michelli, and T. Pickeral. (2009). School Climate: Research, Policy, Practice, and Teacher Education. Teachers College Record, 111, $180-213$.

Harris, J., Caldwell, B., \& Longmuir, F. (2013). Literature Review: a culture of trust enhances performance. Australian Institute for Teaching and School Leadership.

Henderson, A. T., Mapp K. L. (2002). A New Wave of Evidence: The Impact of School, Family, and the Community Connections on Student Achievement. SEDL.

Ilgan, A., Ata, A., Zepeda, S. J., Ozu-Cengiz, O. (2014). Validity and reliability study of Quality of School Work Life (QSWL) scale. International Journal of Human Sciences, 11(2), 114-137.

Lenzi, M., Sharkey, J., Furlong, M. J., Mayworm, A., Hunnicutt, K., \& Vieno, A. (2017). School Sense of Community, Teacher Support, and Students' School Safety Perceptions. American Journal of Community Psychology, 60(3-4), 527-537. https://doi.org/10.1002/ ajcp. 12174

Maier, A., Daniel, J., Oakes, J. and Lam, L. (2017). Community schools as an effective school improvement strategy. A review of the evidence. Palo Alto, CA: Learning Policy Institute.

Sheldon, S. (2007). Improving Student Attendance with School, Family, and Community Partnerships. The Journal of Education Research, 100(5), 267-275, DOI: 10.3200/ JOER.100.5.267-275 
Sheldon, S., Epstein, J. (2004). Getting Students to School: Using Family and Community Involvement to Reduce Chronic Absenteeism. School Community Journal, 14(2), 39-6.

Smetackova, I., Viktorova, I., Martanova, V., Pachova. A., Francova Vand Stech, S. (2019). Teachers Between Job Satisfaction and Burnout Syndrome: What Makes Difference in Czech Elementary Schools. Frontiers in Psychology (10) 22-87.

Solomon, D., Battistich, V., Watson, M., Schaps, E., \& Lewis, C. (2000). A six-district study of educational change: Direct and mediated effects of the Child Development Project. Social Psychology of Education, 4, 3-51.

Thomas, K. J., Santo, J. B., \& da Cunha, J. M. (2019). The predictive value of school climate and teacher techniques on students' just world beliefs: A comprehensive Brazilian sample. Social Psychology of Education, 22(5), 1239-1257. https://doi.org/10.1007/ s11218-019-09524-3

Van Eck, K., Johnson, S. R., Bettencourt, A., \& Johnson, S. L. (2017). How school climate relates to chronic absence: A multi-level latent profile analysis. Journal of School Psychology, 61, 89-102. https://doi.org/10.1016/j.jsp.2016.10.001 